\title{
REGULAÇÃO E QUALIDADE: CONCEITOS IMBRICADOS NAS POĹTICAS DE AVALIAÇÃO E DE FORMAÇÃO DE PROFESSORES
}

\author{
REGULATION AND QUALITY: CONCEPTS IMPROVED IN EVALUATION \\ AND TEACHER TRAINING POLICIES
}

\author{
REGULACIÓN Y CALIDAD: CONCEPTOS IMBRICADOS EN LAS POLÍTICAS DE \\ EVALUACIÓN Y DE FORMACIÓN DE MAESTROS
}

\section{Mônica de Souza Trevisan ${ }^{1}$ Rosane Carneiro Sarturi ${ }^{2}$}

\begin{abstract}
RESUMO
Este artigo tem o objetivo identificar os conceitos de regulação e qualidade presentes nos documentos legais, que regem as políticas públicas de avaliação da educação superior e de formação de professores, visando estabelecer as relações entre estas políticas. O problema de pesquisa assim se apresenta: como as políticas públicas de formação de professores para a educação básica e de avaliação da educação superior podem estar relacionadas com a regulação e a qualidade? O trabalho fundamenta-se na pesquisa bibliográfica e documental, pois, utilizamos documentos como: as Diretrizes Curriculares Nacionais para a formação inicial e continuada de professores da educação básica, conforme Resolução CNE/CP n. ${ }^{\circ}$ 2/2015 (BRASIL, 2016a); o Instrumento de Avaliação de Cursos de Graduação Presencial e a política de avaliação para a Educação Superior, especificamente a Lei n. ${ }^{\text {1 }}$ 10.861/2004 que estabelece o Sistema Nacional de Avaliação da Educação Superior (Sinaes). O conceito de qualidade fundamenta-se principalmente em Morosini, e o de regulação em Barroso. Observamos que regulação e qualidade estão presentes em ambas as políticas e são relacionados com a forma em que se propõe avaliar as licenciaturas. A avaliação ganha relevância na atual política de formação de professores que traz na Resolução CNE/CP n. ${ }^{\circ}$ 2/2015 a preocupação explicita com padrão de qualidade para os cursos de licenciatura.
\end{abstract}

PALAVRAS-CHAVE: Regulação. Qualidade. Sinaes. Formação de professores.

\begin{abstract}
This article aims to identify the concepts of regulation and quality present in legal documents, which govern the public policies for the evaluation of higher education and teacher training, aiming to establish the relationships between these policies. The research problem is: how can public education policies for teachers of basic education and higher education be related to regulation and quality? The work is based on bibliographical and documentary research, therefore, we use documents such as: The National Curricular Guidelines for the teachers initial and continuing training of basic education, According to CNE / CP. n. ${ }^{\circ}$ 2/2015; The Instrument for the Evaluation of Distance and Online Undergraduate Courses, and the evaluation policy for Higher Education, specifically the law n. ${ }^{\circ}$ 10.861/2004 Which establishes the National System of Evaluation of Higher Education (Sinaes). The concept of quality is based mainly on Morosini, and the regulation in Barroso. We observed that regulation and quality are present in both policies and are related to the way in which it is proposed to evaluate
\end{abstract}

\footnotetext{
${ }^{1}$ Doutoranda em Educação. Pedagoga da carreira de Técnico-Administrativo em Educação na Universidade Federal do Pampa. e-mail: monicastrevisan@gmail.com - ORCID: http://orcid.org/0000-0002-2979-0697 ${ }^{2}$ Professora Associada II da Universidade Federal de Santa Maria. Professora no Programa de Pós-Graduação em Educação, do Centro de Educação da UFSM. E-mail: rcsarturi@gmail.com - ORCID: http://orcid.org/00000002-5947-6041
}

Submetido em: 03/11/2016 - Aceito em: 05/12/2016

\begin{tabular}{l|l|l|l|l|l|l} 
(C) Rev. Inter. Educ. Sup. & Campinas, SP & v.2 & n.3 & p.387-404 & set/dez. 2016 & ISSN 2446-9424
\end{tabular}


the degrees. The evaluation gains importance in the current policy of teacher training that brings in Resolution $\mathrm{CNE} / \mathrm{CP} \mathrm{n}^{\circ}$ 2/2015 the explicit concern with a quality standard for undergraduate courses.

KEYWORDS: Regulation. Quality. Sinaes. Teacher training.

\section{RESUMEN}

Este artículo presenta como objetivo identificar los conceptos de regulación y calidad presentes en los documentos legales, que orientan a las políticas públicas de evaluación de la educación superior e de formación de maestros, teniendo en vista establecer las relaciones entre estas políticas. El problema de investigación se presenta: Cómo las políticas públicas de formacíon de maestros y de evaluación de la educacíon superior pueden estar relacionados con regulación y la calidad. El trabajo se fundamenta en la investigación bibliográfica y documental, pues hemos hecho uso de documentos tales como: Directrices Curriculares Nacionales para la

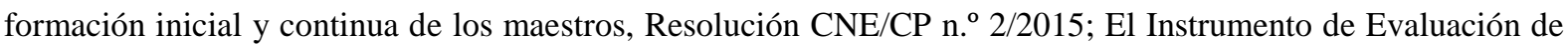
Carreras de Grado presencial y la distancia, y la política de evaluación para la Educación Superior, en específico la Ley n. ${ }^{\circ}$ 10.861/2004 - Ley del Sistema Nacional de Evaluación de la Educación Superior (Sinaes). El concepto de calidad se basa principalmente en Morosini, y el de regulación en Barroso. Se observó que la regulación y la calidad están presentes tanto en la política de evaluación, como en la de formación de maestros, y además son relacionadas con la forma en que se propone evaluar las carreras de grado para maestros. La evaluación se converte relevante en la política actual de formación de maestros que presenta en la Resolución CNE/CP n. ${ }^{\circ}$ 2/2015 la preocupación explícita con la padronización de la calidad para los cursos de grado que forman maestros.

PALABRAS CLAVE: Regulación. Calidad. Sinaes. Formación de maestros.

\section{Introdução}

Neste breve artigo pretendemos abordar duas políticas públicas educacionais que são complexas: a avaliação e a formação de professores. Não haverá o detalhamento de uma e de outra política, mas as possíveis relações que podem se estabelecer entre ambas.

Partimos do princípio de que avaliar é pertinente e necessário, mas avaliar como e porquê? O que a política de avaliação da educação superior está induzindo ou prevendo para os cursos de formação de professores no Brasil, que a partir da aprovação da Resolução CNE/CP n. ${ }^{\circ}$ 2/2015 (BRASIL, 2016a)? Como será feira a reformulação dos currículos dos cursos adequando-os a nova resolução? Estas não são respostas simples no momento político vivenciado atualmente no Brasil, servem de reflexão para colocarmos nosso problema: como as políticas públicas de formação de professores para a educação básica e de avaliação da educação superior podem estar relacionadas com a regulação e a qualidade? Assim, pretendemos apresentar os conceitos de regulação e qualidade e suas relações com as políticas de avaliação da educação superior e formação de professores.

Para descrever e interpretar tais políticas utilizou-se os fundamentos da pesquisa bibliográfica e documental, conforme Gil (2011), de modo a buscar conceituar a regulação (BARROSO, 2005; 2006) e a qualidade (MOROSINI, 2001; 2009). Os documentos consultados em relação a política de formação de professores foram as Diretrizes Curriculares Nacionais (DCNs) para a formação inicial e continuada de professores da educação básica, aprovadas pela

\begin{tabular}{l|l|l|l|l|l|l} 
(C) Rev. Inter. Educ. Sup. & Campinas, SP & v.2 & n.3 & p.387-404 & set/dez. 2016 & ISSN 2446-9424 \\
\hline
\end{tabular}


Resolução CNE/CP n. ${ }^{0}$ 02/2015 (BRASIL, 20016a) e o Documento Base da Comissão SEB/MEC publicado em fevereiro de 2016: Orientações para cursos de Formação de Professores nas áreas de Didática, Metodologias e Práticas de Ensino (BRASIL, 2016b).

Os documentos consultados em relação a política de avaliação foram a Lei n. ${ }^{0}$ 10.861/2004 que institui o Sistema Nacional de Avaliação da Educação Superior (Sinaes) (BRASIL, 2004) e o Instrumento de Avaliação de Cursos de Graduação Presencial e a Distância (INSTITUTO NACIONAL DE ESTUDOS E PESQUISAS EDUCACIONAIS ANÍSIO TEIXEIRA, 2016). Estes documentos deram uma dimensão de como está presente a questão da regulação e da qualidade na configuração da avaliação da Educação Superior brasileira, especialmente avaliação externa e nas atuais Diretrizes para a formação de professores.

Justificamos a importância de discutir as relações presentes entre as políticas no que se referem aos conceitos de regulação e de qualidade que por vezes demonstram uma contradição, pois aparecem concomitantemente, em especial no texto da Lei do Sinaes, propondo um processo de avaliação ao mesmo tempo formativo, participativo e regulatório.

\section{Política de Avaliação}

A política de avaliação da educação superior é vigente no Brasil desde 2004 e organiza-se a partir de três eixos: avaliação institucional; de cursos de graduação e Exame Nacional de Desempenho do Estudante - ENADE. O Sinaes promove a avaliação externa coordenada pelo Instituto Nacional de Estudos e Pesquisas Educacionais Anísio Teixeira (INEP), e interna em cada instituição, por meio de uma Comissão Própria de Avaliação (CPA). Ainda, o funcionamento das instituições de educação superior assim como seus cursos é regulado pelo Ministério da Educação (MEC). Para funcionarem regularmente as instituições dependem do Credenciamento e Recredenciamento e os cursos de Autorização, Reconhecimento e Renovação de reconhecimento, devendo ser renovados periodicamente, conforme determina o artigo 46 da Lei n. ${ }^{\circ}$ 9.394/199 (BRASIL, 1996). Estes atos são expedidos pelo Ministro da Educação condicionados aos resultados satisfatórios nas avaliações do Sinaes, que constituem referencial básico dos processos de regulação conforme determina o parágrafo único do artigo $2^{\circ}$ da Lei 10.861/2004 (BRASIL, 2004).

O Sinaes tem como princípios: a globalidade, a transparência, o respeito a autonomia e alcance da eficácia e efetividade acadêmica institucional (BRASIL, 2004). O processo de avaliação que se desenvolve hoje é bastante complexo e contraditório, a tese de Griboski (2014) analisa a avaliação dos cursos de Pedagogia abrangendo três ciclos, aponta que há contradições no Sistema, entre elas, almejar a qualidade das instituições e cursos, mas alcançar principalmente a regulação deste sistema, remetendo o desenvolvimento da qualidade em segundo plano.

A Lei do Sinaes tem o papel de regular, mas não somente, pois tem entre seus princípios o

\begin{tabular}{l|l|l|l|l|l|l} 
(C) Rev. Inter. Educ. Sup. & Campinas, SP & v.2 & n.3 & p.387-404 & set/dez. 2016 & ISSN 2446-9424 \\
\hline
\end{tabular}


desenvolvimento da qualidade, como alcançá-la, para além de uma avaliação burocrática que atenda exclusivamente as exigências regulatórias?

A política de avaliação é a principal forma de regular o sistema, e o faz utilizando-se também das Diretrizes Curriculares Nacionais para os cursos de Licenciatura que define a organização dos currículos. A partir das definições destas Diretrizes é que a avaliação dos cursos de graduação organiza seus instrumentos. Portanto, a regulação permeia todo o processo de avaliação, que entendemos como um processo contínuo e que tem consequências e repercussões constantes no modo de pensar currículo dos cursos.

\section{Política de Formação de Professores}

As Diretrizes Curriculares Nacionais para formação de professores aprovada pela Resolução CNE/CP n. . 2/2015 (BRASIL, 2016a) aponta para a formação e valorização dos professores da Educação Básica considerando as atividades de docência, gestão e a complexidade das atividades pedagógicas. As Diretrizes abordam a formação inicial e continuada para as funções de magistério da educação básica em todas as suas etapas:

[...] a partir de compreensão ampla e contextualizada de educação e educação escolar, visando assegurar a produção e difusão de conhecimentos de determinada área e a participação na elaboração e implementação do projeto político-pedagógico da instituição, na perspectiva de garantir, com qualidade, direitos e objetivos de aprendizagem e o seu desenvolvimento, a gestão democrática e a avaliação institucional. (BRASIL, 2016a).

As atuais Diretrizes definem a formação de professores pautada em princípios como o respeito a diversidade étnico raciais, de gênero, as diferenças nas aprendizagens, as diferenças regionais do País e o pluralismo de ideias (BRASIL, 2016a). São princípios que consideramos essenciais para a formação de professores e que necessita ser pensado e planejado como estes princípios estarão presentes nos currículos dos cursos de formação inicial e continuada de professores.

Destacamos ainda a compreensão de docência expressa pela Resolução CNE/CP n. ${ }^{\circ}$ 2/2015:

\footnotetext{
Compreende-se a docência como ação educativa e como processo pedagógico intencional e metódico, envolvendo conhecimentos específicos, interdisciplinares e pedagógicos, conceitos, princípios e objetivos da formação que se desenvolvem na construção e apropriação dos valores éticos, linguísticos, estéticos e políticos do conhecimento inerentes à sólida formação científica e cultural do ensinar/aprender, à socialização e construção de conhecimentos e sua inovação, em diálogo constante entre diferentes visões de mundo. (BRASIL, 2016a).
}

A docência exige uma formação complexa, tendo a formação inicial como momento privilegiado para o desenvolvimento de conhecimentos e valores que constituem a ação profissional dos professores. A formação continuada articulada com a formação inicial, entendida como "componente essencial da profissionalização inspirado nos diferentes saberes e na experiência docente, integrando-a ao cotidiano da instituição educativa [...]” (BRASIL,

\begin{tabular}{l|l|l|l|l|l|l} 
(C) Rev. Inter. Educ. Sup. & Campinas, SP & v.2 & n.3 & p.387-404 & set/dez. 2016 & ISSN 2446-9424
\end{tabular}


2016a). A formação nos cursos de licenciatura e de formação continuada exigirá um envolvimento colaborativo entre os entes federados, as instituições formadoras, as redes escolares de educação básica, os gestores e professores, além de investimento sério e planejado para que se desenvolva conforme preceituam as Diretrizes.

Outro destaque necessário refere-se a relação teórico-prática, que constitui princípio para a formação de profissionais do magistério da educação básica: “[...] a articulação entre a teoria e a prática no processo de formação docente, fundada no domínio dos conhecimentos científicos e didáticos, contemplando a indissociabilidade entre ensino, pesquisa e extensão” (BRASIL, 2016a). Neste sentido é necessária a discussão sobre esta relação concebendo que o projeto de formação nos cursos de licenciatura deve ser elaborado em articulação entre instituições formadoras, escolas de educação básica, fóruns permanentes de discussão envolvendo pesquisadores e profissionais da área.

Conforme Dourado (2015) estas são questões que suscitam pensar a dinâmica formativa dos profissionais, garantido o direito da formação a sujeitos e grupos muitas vezes à margem do direito a educação, exigindo uma transformação no modo como as instituições de educação básica e superior estruturam os espaços e tempos, as suas regras, ao modo de incorporar novos materiais e recursos pedagógicos, o modo como pensam e desenvolvem o currículo dos cursos de licenciatura e de formação continuada.

Em síntese a formação de professores no Brasil necessita um trabalho contínuo de aprimoramento. Contundentemente, a Resolução CNE/CP n. ${ }^{0}$ 02/2015 (BRASIL, 2016a) aponta a necessidade de pensar articuladamente formação inicial e continuada, com base em uma formação teórico-prática, articulando as ações entre escola e universidade, redes públicas de ensino, entidades e associações de pesquisadores em educação. Dourado (2015) indica que a construção da proposta das atuais diretrizes ocorreram com diversas instâncias de participação que envolveu Secretarias do MEC, associações e entidades como: Associação Nacional de Política e Administração da Educação (ANPAE); Associação Nacional de Pesquisadores em Educação (ANPED) Coordenação de Aperfeiçoamento de Pessoal de Nível Superior (CAPES); Fórum Nacional de Diretores de Faculdades, Centros de Educação ou Equivalentes das Universidades Públicas Brasileiras (FORUMDIR); União Nacional dos Dirigentes Municipais de Educação (UNDIME); Universidades e grupos envolvidos com a formação de professores no País. Tal movimento, ocorreu previamente a aprovação das Diretrizes, em fóruns, momentos de discussão e consultas públicas, o que segundo Dourado (2015) facilitou o processo de aprovação no Conselho Nacional de Educação (CNE).

As diretrizes reafirmam as Instituições de Educação Superior (IES) como o local essencial da formação de professores, numa perspectiva de articulação conforme afirma Dourado (2015, p. 315.), “[...] entendemos que esta perspectiva articulada a centralidade conferida à formação dos profissionais do magistério da educação básica pode contribuir para a superação da dicotomia entre teoria e prática, bacharelado e licenciatura” A superação da fragmentação na

\begin{tabular}{l|l|l|l|l|l|l} 
(C) Rev. Inter. Educ. Sup. & Campinas, SP & v.2 & n.3 & p.387-404 & set/dez. 2016 & ISSN 2446-9424
\end{tabular}


formação de professores seria um passo muito importante para impulsionar melhorias na Educação Básica, mas desde a aprovação das diretrizes em julho de 2015 até o momento atual, muitas mudanças ocorreram no cenário político brasileiro gerando descontinuidade e um clima de incertezas no meio educacional. Até o momento, a Resolução CNE/CP n. ${ }^{\circ}$ 2/2015 (BRASIL, 2016a) está vigente e estabelece em seu art. 22 um prazo de dois anos para a adaptação dos cursos, que expira em 2017.

\section{A Qualidade nos Documentos Analisados}

A legislação referente a avaliação e a formação de professores traz, em diferentes momentos, a palavra qualidade. Recortamos nove trechos divididos em dois quadros, explicitando a palavra qualidade conforme a Resolução CNE/CP n. ${ }^{\circ}$ 2/2015.

No quadro 1: Padrão de qualidade e a relação com o Sinaes, observamos nos trechos da Resolução CNE/CP n. ${ }^{0}$ 2/2015 que a palavra qualidade aparece relacionada a avaliação e ao Sinaes nos trechos I e II. No excerto III, aparece também relacionada a qualidade na educação básica, buscando assegurar o direito a educação de qualidade, considerando as etapas da Educação Infantil, Ensino Fundamental e Ensino Médio. A ideia de padrão de qualidade também é retomada no sentido de qualidade acadêmica como é possível observar no excerto IV que aponta a necessidade de pensar ensino, pesquisa e extensão de modo articulado na formação de professores, fazendo-se necessária a parceria entre Estados e Municípios com suas redes de Educação Básica e Instituições de Educação Superior.

Nota-se que a exigência da relação entre ensino, pesquisa e extensão, prioriza pensar a formação de professores ultrapassando algumas das dicotomias que ainda estão presentes nas concepções da formação de professores como teoria versus prática; saberes pedagógicos versus conhecimentos específicos da área. Para superação desta dicotomia as DCNs propõem “mover-se no campo” (BRASIL, 2016b), bem como a “[...] compreensão dos aspectos filosóficos, históricos, políticos e sociológicos da educação, integrando esses conhecimentos para a compreensão da realidade educacional de forma a permitir orientar suas práticas profissionais”. (BRASIL, 2016b). Esta necessidade possibilita pensar a qualidade de modo mais ampliado do que somente por padrões, ou seja, a qualidade também é social. E por isso este termo está repleto de múltiplos significados, mas por sua polissemia é utilizado acompanhado do termo padrão, e do significado de regulação. Mas é importante sublinhar a diferença entre regulação e qualidade.

Quadro 1 - Padrão de qualidade e a relação com o Sinaes

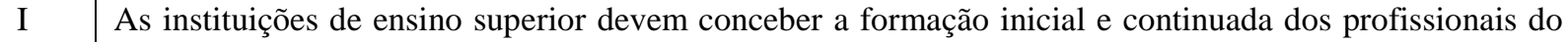
magistério da educação básica na perspectiva do atendimento às políticas públicas de educação, às Diretrizes Curriculares Nacionais, ao padrão de qualidade e ao Sistema Nacional de Avaliação da Educação Superior (Sinaes), manifestando organicidade entre o seu Plano de Desenvolvimento Institucional (PDI), seu Projeto Pedagógico Institucional (PPI) e seu Projeto Pedagógico de Curso (PPC)

\begin{tabular}{l|l|l|l|l|l|l} 
(C) Rev. Inter. Educ. Sup. & Campinas, SP & v.2 & n.3 & p.387-404 & set/dez. 2016 & ISSN 2446-9424
\end{tabular}




\begin{tabular}{|c|c|}
\hline & U vastea, suds \\
\hline II & $\begin{array}{l}\text { Os centros de formação de estados e municípios, bem como as instituições educativas de educação básica } \\
\text { que desenvolverem atividades de formação continuada dos profissionais do magistério, devem concebê- } \\
\text { la atendendo às políticas públicas de educação, às Diretrizes Curriculares Nacionais, ao padrão de } \\
\text { qualidade e ao Sistema Nacional de Avaliação da Educação Superior (Sinaes), expressando uma } \\
\text { organicidade entre o seu Plano Institucional, o Projeto Político Pedagógico (PPP) e o Projeto Pedagógico } \\
\text { de Formação Continuada (PPFC) através de uma política institucional articulada à educação básica, suas } \\
\text { políticas e diretrizes. }\end{array}$ \\
\hline III & $\begin{array}{l}\text { Princípios da Formação de Profissionais do Magistério da Educação Básica: } \\
\text { I - a formação docente para todas as etapas e modalidades da educação básica como compromisso } \\
\text { público de Estado, buscando assegurar o direito das crianças, jovens e adultos à educação de } \\
\text { qualidade, construída em bases científicas e técnicas sólidas em consonância com as Diretrizes } \\
\text { Curriculares Nacionais para a Educação Básica; } \\
\text { IV - a garantia de padrão de qualidade dos cursos de formação de docentes ofertados pelas } \\
\text { instituiçôes formadoras. }\end{array}$ \\
\hline IV & $\begin{array}{l}\text { Art. } 4^{0} \text { A instituição de educação superior que ministra programas e cursos de formação inicial e } \\
\text { continuada ao magistério, respeitada sua organização acadêmica, deverá contemplar, em sua dinâmica e } \\
\text { estrutura, a articulação entre ensino, pesquisa e extensão para garantir efetivo padrão de qualidade } \\
\text { acadêmica na formação oferecida, em consonância com o Plano de Desenvolvimento Institucional } \\
\text { (PDI), o Projeto Pedagógico Institucional (PPI) e o Projeto Pedagógico de Curso (PPC). } \\
\text { Parágrafo único. Os centros de formação de Estados e Municípios, bem como as instituições educativas } \\
\text { de educação básica que desenvolverem atividades de formação continuada dos profissionais do } \\
\text { magistério, deverão contemplar, em sua dinâmica e estrutura, a articulação entre ensino e pesquisa, } \\
\text { para garantir efetivo padrão de qualidade acadêmica na formaçãa oferecida, em consonância com o } \\
\text { plano institucional, o projeto político-pedagógico e o projeto pedagógico de formação continuada }\end{array}$ \\
\hline
\end{tabular}

Fonte: Resolução CNE/CP n. ${ }^{\circ}$ 2/2015, grifo nosso. (BRASIL, 2016a).

Para além das medições e das definições de padrão, veremos que as DCNs apontam para a qualidade social, no sentido de busca pela valorização dos profissionais da Educação, e de compreensão da importância de valorização do direito a educação básica de qualidade. Jornet (2012) defende a necessidade de haver modelos educativos que sustentem a dimensão de coesão social:

Es cierto que en Educación se trata de la equidad, la inclusión, la diversidad (sea étnica, de género, de origen multicultural...). La conciencia está claro que existe, aunque no se haya identificado dentro del modelo de acción mencionado. Y, si se me permite, no sólo existe, sino que quizás entre los educadores es donde mayor masa crítica de personas que comparten estas expectativas podríamos encontrar [...] Es necesario hacer un esfuerzo para intentar acercarnos a un modelo o modelos educativos que explícitamente afronten el problema de la promoción de la cohesión social. (JORNET, 2012, p. 351).

A ideia de equidade está relacionada também a coesão social, Dias Sobrinho fala de qualidade social e os múltiplos sentidos que pode envolvê-la:

Uma vez que a qualidade educativa é sempre concernida pela qualidade social, vale dizer, é relativa à qualidade da sociedade que queremos para hoje e projetamos para as próximas gerações, seu conceito não é unívoco, nem fixo, e só pode ser construído por consensos, como resultado das relações de força. (DIAS SOBRINHO, 2011, p. 60).

As Diretrizes também foram construídas, como vimos, com a discussão feita a partir de diversos grupos representativos, o que aponta no texto a necessidade de pensar esta qualidade também em relação a sociedade, aos professores e aos alunos, prementemente, aos recursos e

\begin{tabular}{|c|c|c|c|c|c|c|}
\hline (C) Rev. Inter. Educ. Sup. & Campinas, SP & v.2 & n.3 & p.387-404 & set/dez. 2016 & ISSN $2446-9424$ \\
\hline
\end{tabular}


a gestão. Assim selecionamos no Quadro 2 mais cinco excertos que se relacionam aos aspectos mencionados sobre qualidade.

Quadro 2 - Qualidade Social e valorização profissional

\begin{tabular}{|c|c|}
\hline I & $\begin{array}{l}\text { 30 A formação inicial e a formação continuada destinam-se, respectivamente, à preparação e ao } \\
\text { envolvimento de profissionais para funções de magistério na educação básica em suas etapas - } \\
\text { icação infantil, ensino fundamental, ensino médio - e modalidades - educação de jovens e adultos, } \\
\text { icação especial, educação profissional e técnica de nível médio, educação escolar indígena, educação } \\
\text { campo, educação escolar quilombola e educação a distância - a partir de compreensão ampla e } \\
\text { textualizada de educação e educação escolar, visando assegurar a produção e difusão de } \\
\text { hecimentos de determinada área e a participação na elaboração e implementação do projeto político- } \\
\text { lagógico da instituição, na perspectiva de garantir, com qualidade, os direitos e objetivos de } \\
\text { rendizagem e o seu desenvolvimento, a gestão democrática e a avaliação institucional. }\end{array}$ \\
\hline II & $\begin{array}{l}\text { nstitui processo dinâmico e complexo, } \\
\text { Icação e à valorização profissional, } \\
\text { derados nos respectivos sistemas de }\end{array}$ \\
\hline III & $\begin{array}{l}\text { so: } \\
\text { internacionais de pesquisa, ao material de apoio pedagógico de } \\
\text { produção acadêmica-profissional, viabilizando os programas de } \\
\text { básica; } \\
\text { blioteca, laboratórios, videoteca, entre outros, além de recursos de } \\
\text { Inicação, com qualidade e quantidade, nas instituições de formação; }\end{array}$ \\
\hline IV & $\begin{array}{l}\text { t. 16, parágrafo único a concepção de profissional a ser considerada na formação continuada, } \\
\text { luindo: [...] } \\
\text { - O diálogo e a parceria com atores e instituições competentes, capazes de contribuir para } \\
\text { vancar novos patamares de qualidade ao complexo trabalho de gestão da sala de aula e da } \\
\text { tituição educativa. }\end{array}$ \\
\hline $\mathrm{V}$ & $\begin{array}{l}\text { Art. 19. Como meio de valorização dos profissionais do magistério público nos planos de carreira e } \\
\text { remuneração dos respectivos sistemas de ensino, deverá ser garantida a convergência entre formas de } \\
\text { acesso e provimento ao cargo, formação inicial, formação continuada, jornada de trabalho, incluindo } \\
\text { horas para as atividades que considerem a carga horária de trabalho, progressão na carreira e avaliação de } \\
\text { desempenho com a participação dos pares, asseverando-se: } \\
\text { I - Acesso à carreira por concurso de provas e títulos orientado para assegurar a qualidade da ação } \\
\text { educativa. [...] } \\
\text { V - Manutenção de comissão paritária entre gestores e profissionais da educação e os demais setores da } \\
\text { comunidade escolar para estudar as condições de trabalho e propor políticas, práticas e ações para o }\end{array}$ \\
\hline
\end{tabular}

Fonte: Resolução CNE/CP n. ${ }^{0}$ 2/2015, grifo nosso. (BRASIL, 2016a).

No excerto I a qualidade aparece relacionada ao direito de aprender e a necessidade de desenvolver a formação de professores com vistas a participação e a gestão democrática, isso implica na formação para a gestão, retomada no excerto IV, concebendo que a gestão é da sala de aula e da instituição educativa, este profissional, necessariamente precisa saber dialogar e promover a gestão democrática.

Ainda queremos destacar a qualidade social, associada a valorização do profissional, o acesso a carreira, o acompanhamento das condições de trabalhos, conforme trechos II e V. Podemos compreender que a resolução aborda qualidade no sentido de respeito a autonomia, diversidade, preocupação com o desenvolvimento de oportunidades justas, no sentido de equidade, conforme Morosini (2009). 
A qualidade como sinônimo de equidade é defendida também pela Organização das Nações Unidas para e Educação Ciência e Cultura - UNESCO, e tem como dimensões a justiça e a inclusão. (MOROSINI, 2009).

Por fim, conforme excerto III, a ideia de qualidade aparece também quando aponta a preocupação com os recursos utilizados no decorrer da formação, relacionando toda a infraestrutura necessária para o curso de formação de professores compreendendo literatura atualizada, tempo para estudo, produção e pesquisa, recursos de tecnologias e informação e comunicação.

Assim sendo, cada curso, ao repensar seu currículo a partir das novas DCNs, por meio dos seus Núcleos Docentes Estruturantes (NDE) está envolvido com a questão da qualidade: Com que qualidade pretende desenvolver a formação inicial ou continuada de professores? $\mathrm{O}$ padrão de qualidade que se relaciona com a regulação.

\section{A regulação e o padrão de qualidade}

Ao reafirmar padrão de qualidade referido na Resolução CNE/CP n. ${ }^{\circ}$ 2/2015 observamos então a relação com o Sinaes, seus instrumentos e índices que são os definidores de padrões. O Instrumento de Avaliação de Cursos de Graduação Presencial e a Distância (INSTITUTO NACIONAL DE ESTUDOS E PESQUISAS EDUCACIONAIS ANÍSIO TEIXEIRA, 2016), formulado com indicadores e utilizado para as avaliações externas realizadas in loco.

O INEP coordena o processo de avaliação externa, designando comissões de pares para avaliar os cursos com a finalidade de autorizar, reconhecer ou renovar o reconhecimento dos cursos. Destaca-se que a renovação de reconhecimento só ocorre por meio de visita in loco, se o curso não tiver Conceito Preliminar de Curso (CPC), ou se o conceito obtido for um ou dois, considerado insatisfatório, estas determinações são de ordem regulatória disponibilizada em Nota Técnica do MEC, como por exemplo a Nota Técnica n 50006/2015/DIREG/SERES (BRASIL, 2016d) que sistematiza os procedimentos para a renovação de reconhecimento dos cursos, tendo como referência o CPC. O CPC foi criado em 2008, pela Portaria Normativa ${ }^{\circ}$ 4/2008 (BRASIL, 2008), e conforme expressa a Nota Técnica n. ${ }^{\circ}$ 786/2013 DIREG/SERES/MEC (BRASIL, 2016c) é indicador de qualidade para os cursos, calculado com base no ENADE e em outros insumos.

Estes dispositivos legais são exemplos da operacionalização dos processos de regulação no Sinaes, no sentido normativo. A regulação é um pressuposto da política de avaliação que tem por finalidade garantir a qualidade, entretanto não pode ser vista como preponderante considerando os princípios de transparência e a globalidade presentes no Sinaes.

Segundo Griboski (2014) tem ocorrido uma supervalorização da regulação o que acaba desequilibrando o sistema, utilizando-se de indicadores de qualidade como CPC e Índice

\begin{tabular}{l|l|l|l|l|l|l} 
(C) Rev. Inter. Educ. Sup. & Campinas, SP & v.2 & n.3 & p.387-404 & set/dez. 2016 & ISSN 2446-9424
\end{tabular}


Geral de Cursos (IGC) supervalorizados pelos processos regulatórios em detrimento dos processos de avaliação presencial com a visita in loco das comissões de pares externas. Além disso, a questão da autoavaliação desenvolvida internamente nas IES deve ser muito bem valorizada pela própria gestão institucional, do contrário, perdemos a possibilidade de participação e envolvimento da comunidade acadêmica. A avaliação necessita valorizar processo e resultado, conjuntamente.

\begin{abstract}
Contudo, a criação do CPC e do IGC em 2008, ambos indicadores de qualidade constituídos, em grande parte, por insumos extraídos do Enade, têm colocado os resultados da avaliação in loco de cursos (CC) e de instituições (CI) em situação de descaso pela regulação. $\mathrm{O}$ uso da avaliação como resultado que serve à punição, sustentada na aplicação de medidas regulatórias, acaba por enfraquecer o processo de avaliação como preditor da qualidade. (GRIBOSKI, 2014, p. 128).
\end{abstract}

A contradição entre regulação e qualidade merece atenção, pois cada vez mais a legislação aponta para a necessidade de avaliação, mas o processo todo não pode perder sentido e tornar-se mero acúmulo de dados quanti-qualitativos que em seu conjunto não fazem sentido para a instituição/cursos, melhorarem o seu fazer cotidiano. Apenas os processos regulatórios não garantem a visão de qualidade dos cursos de Licenciatura perante a complexidade apontada pelas novas DCNs na Resolução CNE/CP nº 02/2015 e pelo contexto da Educação Básica.

Buscamos os indicadores de avaliação do Instrumento de Avaliação de Cursos de Graduação Presencial e a Distância (INSTITUTO NACIONAL DE ESTUDOS E PESQUISAS EDUCACIONAIS ANÍSIO TEIXEIRA - INEP, 2016), por considera-los indicativos dos critérios de qualidade para os cursos, e cujo processo de avaliação subsidia a decisão regulatória.

Cada indicador é avaliado com conceitos de um a cinco, entre níveis de inexistente a excelente, atribuindo conceito um para não há ou inexistente; dois para insuficiente; três para suficiente; quatro para muito bom; e cinco para excelente. Consta no quadro a dimensão e o indicador, o descritor para cada conceito encontra-se detalhadamente no Instrumento de Avaliação de Cursos de Graduação Presencial e a Distância (INEP, 2016).

O quadro 3: Indicadores da dimensão 1 para todos os cursos de graduação aponta os indicadores que avaliam a dimensão organização didático-pedagógica, ao avaliar esta dimensão a comissão subsidia-se no Projeto Político-Pedagógico do curso (PPC), no Plano de Desenvolvimento Institucional (PDI), enfim, faz toda uma leitura de contexto dialogando com professores, alunos e coordenador do curso. 
Quadro 3 - Indicadores da dimensão 1 para todos os cursos de graduação ${ }^{3}$.

\begin{tabular}{|l|l|}
\hline Dimensão & Indicador \\
\hline \multirow{4}{*}{$\begin{array}{l}\text { 1- Organização } \\
\text { didático- }\end{array}$} & 1.1. Contexto educacional \\
\cline { 2 - 3 } & 1.2. Políticas institucionais no âmbito do curso \\
\cline { 2 - 3 } & 1.3. Objetivos do curso \\
\cline { 2 - 3 } & 1.4. Perfil profissional do egresso \\
\cline { 2 - 3 } & 1.5. Estrutura curricular \\
\cline { 2 - 2 } & 1.6. Conteúdos curriculares \\
\cline { 2 - 2 } & 1.7. Metodologia \\
\cline { 2 - 2 } & 1.9. Estágio curricular supervisionado \\
\cline { 2 - 3 } & 1.14. Atividades complementares \\
\cline { 2 - 3 } & 1.16. Apoio ao discente \\
\cline { 2 - 2 } & 1.17. Ações decorrentes dos processos de avaliação do curso \\
\cline { 2 - 3 } & 1.22. Procedimentos de avaliação dos processos de ensino-aprendizagem \\
\cline { 2 - 3 } & 1.23. Número de vagas \\
\cline { 2 - 2 } & 1.33. Responsabilidade Social \\
\cline { 2 - 2 } & 1.36. Participação dos discentes no acompanhamento e na avaliação do PPC \\
\hline
\end{tabular}

Fonte: Instrumento de Avaliação de Cursos de Graduação Presencial e a Distância (INEP, 2016).

As informações geradas a partir de um processo de avaliação in loco oferecem uma quantidade de dados que são subsídios para o NDE refletir sobre PPC, toda a dimensão Organização Didático Pedagógica analisará o projeto de curso em questão, a que se propõe e se alcança seus objetivos. É um processo que pode auxiliar o trabalho do NDE de reestruturar os currículos, se acompanhado de processos autoavaliativos. Destacamos o indicador 1.33 Responsabilidade Social, o que é e como desenvolvê-la em um curso de licenciatura? Estas questões têm um potencial de gerar reflexão, de buscar diagnosticar as dificuldades e pensar em possibilidades para o curso.

A dimensão corpo docente e tutorial, como vemos no Quadro 4: Indicadores da dimensão 2 para todos os cursos de graduação, é mais quantitativa, fixando-se em tempo de experiência dos docentes, anos de atuação na educação superior, atuação do Núcleo Docente Estruturante (NDE), atuação do colegiado do curso e equivalente, na produção científica dos docentes, experiência do coordenador do curso, entre outros indicadores, que são pontuados a partir da análise do currículo Lattes e das comprovações de tempo de experiência. Os avaliadores observam as informações disponibilizadas pelo curso, documentos comprobatórios e atas de colegiado, NDE, e currículo dos docentes, além de realizarem reunião com o corpo docente e discente, onde costumam perguntar sobre a gestão do curso, organização curricular, funcionamento do NDE, funcionamento do colegiado, buscando avaliar a partir das informações que colhem por triangulação de dados, utilizando-se das fontes documental fornecida pelo curso, e reunião com coordenação, NDE, docentes, discentes e técnicos administrativos, em momentos diferentes no decorrer da avaliação.

\footnotetext{
${ }^{3}$ No caso dos indicadores específicos de cursos de educação a distância, cursos da área da saúde, incluindo medicina, e curso de direito foram desconsiderados na composição dos quadros, pois não são foco deste trabalho.
}

\begin{tabular}{l|l|l|l|l|l|l} 
(C) Rev. Inter. Educ. Sup. & Campinas, SP & v.2 & n.3 & p.387-404 & set/dez. 2016 & ISSN 2446-9424
\end{tabular}


Quadro 4 - Indicadores da dimensão 2 para todos os cursos de graduação.

\begin{tabular}{|l|l|}
\hline Dimensão & Indicador \\
\hline \multirow{4}{*}{ 2- Corpo docente e } & 2.1. Atuação do Núcleo Docente Estruturante - NDE \\
\cline { 2 - 3 } & 2.2. Atuação do (a) coordenador (a) \\
\cline { 2 - 3 } & 2.3. Experiência de magistério superior e de gestão acadêmica do (a) coordenador (a) \\
\cline { 2 - 3 } & $\begin{array}{l}\text { 2.4. Regime de trabalho do (a) coordenador (a) do curso (somente para curso } \\
\text { presencial). }\end{array}$ \\
\cline { 2 - 3 } & 2.6. Titulação do corpo docente do curso \\
\cline { 2 - 3 } & 2.7. Titulação do corpo docente do curso - percentual de doutores \\
\cline { 2 - 3 } & 2.8. Regime de trabalho do corpo docente do curso \\
\cline { 2 - 3 } & 2.9. Experiência profissional em sua área de atuação docente \\
\cline { 2 - 3 } & 2.11. Experiência de magistério superior do corpo docente \\
\cline { 2 - 3 } & 2.13. Funcionamento do colegiado de curso ou equivalente \\
\cline { 2 - 3 } & 2.14. Produção científica, cultural, artística ou tecnológica \\
\hline
\end{tabular}

Fonte: Instrumento de Avaliação de Cursos de Graduação Presencial e a Distância (INEP, 2016).

A dimensão 3, conforme quadro 5: Indicadores da dimensão 3 para todos os cursos de graduação, avalia a infraestrutura destinada ao curso, e vincula-se a primeira dimensão nos aspectos de bibliografia básica e complementar, periódicos, que seve ser coerente as definições previstas nos planos de estudo do curso, além de estarem atualizadas e disponíveis em quantidade suficiente para o uso dos alunos. Os espaços como laboratórios e seus equipamentos também devem ser coerentes com as práticas previstas no currículo do curso, observemos os indicadores:

Quadro 5 - Indicadores da dimensão 3 para todos os cursos de graduação.

\begin{tabular}{|l|l|}
\hline Dimensão & Indicador \\
\hline \multirow{4}{*}{ - Infraestrutura } & 3.1. Gabinetes de trabalho para professores em Tempo Integral - TI \\
\cline { 2 - 3 } & 3.2. Espaço de trabalho para a coordenação do curso e para os serviços académicos \\
\cline { 2 - 2 } & 3.3. Sala de professores \\
\cline { 2 - 2 } & 3.4. Salas de aula \\
\cline { 2 - 2 } & 3.5. Acesso dos alunos a equipamentos de informática \\
\cline { 2 - 2 } & 3.6. Bibliografia básica \\
\cline { 2 - 2 } & 3.7. Bibliografia complementar \\
\cline { 2 - 2 } & 3.8. Periódicos especializados \\
\cline { 2 - 2 } & 3.9. Laboratórios didáticos especializados ${ }^{4}$ : quantidade \\
\cline { 2 - 2 } & 3.10. Laboratórios didáticos especializados: qualidade \\
\cline { 2 - 2 } & 3.11. Laboratórios didáticos especializados: serviços \\
\hline
\end{tabular}

Fonte: Instrumento de Avaliação de Cursos de Graduação Presencial e a Distância (INEP, 2016).

A última atualização que ocorreu no instrumento de avaliação foi em agosto de 2015,

\footnotetext{
${ }^{4}$ Nos indicadores referentes a laboratórios didáticos especializados consta a seguinte orientação: Para Pedagogia é obrigatório verificar a Brinquedoteca. Para as demais Licenciaturas é obrigatório verificar os respectivos laboratórios de ensino.
}

(C) Rev. Inter. Educ. Sup.

\begin{tabular}{l|l|l|l|l} 
Campinas, SP & v.2 & n.3 & p.387-404 \\
\hline
\end{tabular}

set/dez. 2016

ISSN 2446-9424 
conforme disponibiliza a informação do site do INEP $^{5}$, portanto após a aprovação da Resolução CNE/CP n ${ }^{\circ}$ 02/2015. Apontamos no quadro 6 os indicadores específicos para os cursos de Licenciatura.

Quadro 6 - Indicadores de avaliação específicos para as licenciaturas.

\begin{tabular}{|l|l|}
\hline Dimensão & Indicador \\
\hline \multirow{3}{*}{$\begin{array}{l}\text { Organização didático- } \\
\text { pedagógica }\end{array}$} & $\begin{array}{l}\text { 1.11. Estágio curricular supervisionado - relação com a rede de escolas da } \\
\text { Educação Básica }\end{array}$ \\
\cline { 2 - 2 } & $\begin{array}{l}\text { 1.12. Estágio curricular supervisionado - relação entre licenciandos, docentes e } \\
\text { supervisores da rede de escolas da Educação Básica }\end{array}$ \\
\cline { 2 - 2 } & 1.13. Estágio curricular supervisionado - relação entre teoria e prática \\
\cline { 2 - 2 } & 1.24. Integração com as redes públicas de ensino \\
\cline { 2 - 2 } & 1.29. Atividades práticas de ensino para Licenciaturas \\
\hline Corpo docente e tutorial & 2.10. Experiência no exercício da docência na educação básica \\
\hline
\end{tabular}

Fonte: Instrumento de Avaliação de Cursos de Graduação Presencial e a Distância (INEP, 2016).

A avaliação está direcionando os pontos que são considerados relevantes para a definição de um padrão de qualidade, estes pontos não são fixos, pois o instrumento passa por revisões e reformulações a partir da mudança da legislação. O instrumento apresenta entre seus indicadores a relação com as escolas de educação básica, a integração com as redes públicas de ensino, a necessidade de observar laboratórios dos cursos, para que sejam espaços apropriados para o desenvolvimento das atividades pedagógicas, considerando que o docente em formação desenvolve saberes em unidade teórico-prática que o possibilite considerar “[...] tanto os vários fatores que permeiam a ação pedagógica na educação básica, como o respeito às diferenças socioculturais que caracterizam seu ambiente de trabalho.” (BRASIL, 2016b). O momento de avaliação in loco é importante para que os professores do curso dialoguem com pares externos e reflitam sobre a formação proposta, visando o aprimoramento.

Portanto, a avaliação pode ser potencial para diagnosticar a situação dos cursos e ajudar no planejamento das mudanças propostas pela Resolução CNE/CP n. ${ }^{\circ}$ 2/2015, se não for exclusivamente regulatória como tem sido a tendência de desenvolvimento do Sinaes com a sobreposição de índices em detrimento do processo global de avaliação.

\section{Conceitos Imbricados e Multifacetados}

A avaliação ocupa uma função regulatória como já vimos, e os documentos legais instrumentos e critérios estabelecidos demarcam a existência desta função. Mas são processos são processos que vão conformando nossa ação, a partir da interpretação e ação dos sujeitos via implementação das políticas. Compreendemos deste modo que a regulação e a qualidade

\footnotetext{
${ }^{5}$ Informação disponível em: <http://portal.inep.gov.br/superior-condicoesdeensino-manuais> $>$ Acesso em 20 out. 2016.
} 
são conceitos que estão imbricados nas políticas públicas de avaliação, e que se tornam complexos por seus múltiplos sentidos.

A regulação do sistema educativo não é um processo único, automático e previsível, mas sim um processo compósito que resulta mais da regulação das regulações, do que do controle direto da aplicação de uma regra sobre a ação dos "regulados". (BARROSO, 2005, p. 733).

Para Barroso (2006) a regulação ocorre em diversos níveis: Transnacional; Nacional; Microrregulação local; Metarregulação. Todos estes níveis são fundamentais para compreender os processos avaliativos, desde a formulação das políticas, suas influências internacionais, até a compreensão de suas repercussões nos espaços institucionais e nas pessoas. Assim sendo, é na esfera internacional que circulam as discussões macro a respeito da necessidade de avaliação do Sistema Educacional, assim como os valores e princípios com os quais desenvolve a política que neste ponto já podemos caracterizar por regulatória.

Também é na esfera micro da sala de aula, do curso, em uma instituição que a regulação está presente. A regulação não se confunde com regulamentação, que é o processo de definição e cumprimento das leis, normas e regulamentos, a regulamentação é um dos aspectos, mas não encerra em si toda a característica regulatória.

Ampliando a perspectiva para além da regulamentação compreendemos melhor como podem vir a se desenhar as políticas de formação de professores e de avaliação, assim como suas relações. A formulação destas políticas tem influência transnacional, são desenhadas nacionalmente e passam por processos de micro e Metarregulação, conforme contemplam os níveis descritos por Barroso (2006):

a) Transnacional: refere-se as normas, instrumentos e discursos produzidos em nível internacional e que impactam na formação de políticas nacionais, tem influência de organismos multinacionais como Banco Mundial, Unesco (Organização das Nações Unidas para a Educação, Ciência e Cultura), OCDE (Organização para a Cooperação e Desenvolvimento Econômico).

b) Nacional: ação do Estado no desenvolvimento de políticas em âmbito Nacional, o próprio desenvolvimento das políticas de avaliação e formação de professores. Entendemos conforme Griboski (2014) que o Sinaes é uma forma hibrida de regulação Nacional e Institucional em que ocorre o controle dos resultados da avaliação por parte do Estado no sistema de educação superior e por parte de cada instituição.

[...] “O papel do Estado sobre a coordenação, controle e eficiência sobre o sistema educativo, orientando através de normas, injunções e constrangimentos o contexto da ação dos diferentes atores sociais e seus resultados”. (BARROSO, 2006, p. 50). 
c) Microrregulação local: opera por diferentes lógicas estratégias e racionalidades, pois envolvem-se nela vários atores locais, a complexidade da microrregulação local é comparada a metáfora da rede por Barroso (2006, p. 57) que exemplifica sua ocorrência nas instituições escolares, municípios, em uma relação ao mesmo tempo vertical e horizontal, "entre administradores e administrados” ou entre “diferentes ocupantes de um mesmo espaço de interdependência”, no sentido de que envolve diferentes relações.

d) Metarregulação: o estado deve assumir o papel de regulador das regulações, para "[...] equilibrar a ação das diversas forças em presença, mas também continuar a garantir a orientação global e a transformação do próprio sistema”. (BARROSO, 2006, p. 65).

Entendemos assim que a regulação opera de diversos modos, normatizando e buscando assegurar a consecução de resultados por parte das instituições e dos cursos. Os processos avaliativos têm o papel de regular, assim como necessitam diagnosticar problemas e impulsionar a promoção da qualidade nos cursos e instituições, auxiliando nos processos de gestão amparados por um sentido formativo e emancipador.

Discutimos então sobre que qualidade estamos falando? Alcançar metas quantitativas? Ou desenvolver de fato a formação de professores com vistas a equidade? Estes sentidos desenvolvem-se concomitantemente, disputando espaços.

Morosini (2001) aponta para a concepção de isomorfismo ocorre articulada à ideia de empregabilidade e à lógica de mercado. Relaciona-se a medidas, metas, parâmetros, de acordo com Polidori (2011) a preocupação com a qualidade iniciou no meio empresarial e só depois sistemas de controle e melhoria de qualidade foram sendo implantados nos diversos serviços públicos.

Assim observamos a lógica de mercado no desenvolvimento de políticas e na gestão do sistema educacional, sendo a regulação sempre primazia do Estado. Dale (1994, p. 111) aponta para três questões relacionadas: financiamento, fornecimento e regulação, associadas de diferentes formas. "O Estado pode retirar-se completamente quer do financiamento quer do fornecimento da educação, mas manter a autoridade reguladora que só ele pode exercer, e com ela o controle último do sistema”.

Afonso (1999), demarca a relação intrínseca das relações quase-mercado regulação, avaliações e larga escala e as definições de currículos nacionais:

É, aliás, essa combinação específica de regulação do Estado e de elementos de mercado no domínio público que, na nossa perspectiva, explica que os governos da nova direita tenham aumentado consideravelmente o controle sobre as escolas (nomeadamente pela introdução de currículos e exames nacionais) e, simultaneamente, tenham promovido a criação de mecanismos como a publicitação dos resultados escolares, abrindo espaço para a realização de pressões competitivas no sistema educativo. (p. 144-145). 
O nível de regulação nacional está presente nas definições das políticas que estamos pesquisando, a de avaliação e de formação de professores, que tendem a qualidade isomórfica, mas que ao mesmo tempo, trazem no seu texto a questão da equidade como dimensão prioritária da qualidade, a ser desenvolvida pela política no âmbito das instituições e seus cursos.

\section{Considerações Finais}

Percorremos algumas definições dos conceitos de qualidade conforme Morosini (2001; 2009) e regulação conforme Barroso (2005; 2006). Tais conceitos estão relacionados a política de avaliação da educação superior, assim como a de formação de professores observando que tais políticas se entrecruzam.

A interpretação ocorreu a partir da leitura dos textos legais fundamentada nos conceitos dos autores já citados, em especial no Instrumento de Avaliação de Cursos de Graduação Presencial e a Distância, na Lei $n^{0}$ 10.861/2004 e na Resolução CNE/CP nº 02/2015. Todos estes documentos possibilitam a leitura da qualidade como padrão, e explicitam que a regulação está presente em nosso sistema avaliativo, na definição dos currículos, nos processos legalmente previstos. Entretanto, a Resolução CNE/CP n ${ }^{\circ}$ 02/2015 também aponta para a qualidade no sentido social e da equidade, prevendo uma articulação entre Instituições de Educação Superior e Educação Básica, concebendo a necessidade de valorização profissional, de qualificação da gestão democrática, a partir de uma concepção renovada de formação de professores. Mas não sabemos como e se será implementada a referida resolução.

Compreendemos assim, que, tanto pelo texto da Resolução CNE/CP n. ${ }^{\circ}$ 2/2015, quanto pela Lei n. ${ }^{\circ}$ 10.861/2004 e o Instrumento de Avaliação de Cursos de Graduação Presencial e a Distância, as políticas de avaliação e formação de professores estão inter-relacionadas, e os conceitos de regulação e qualidade com seus sentidos de isomorfismo, qualidade social e equidade estão presentes nos textos analisados. A regulação e a qualidade estão imbricadas, muito embora, pareça ser contraditória esta relação. Partindo do pressuposto de que a regulação é primazia do Estado, como afirmou Dale (1994), a qualidade social e a equidade são processos a serem investigados e aprofundados, mas não descolados da regulação e da contradição que se impõe na relação entre as políticas.

\section{Referências}

AFONSO, A. J. Estado, mercado, comunidade e avaliação: esboço para uma rearticulação crítica. Educação \& Sociedade, Campinas, SP, v. 20, n. 69, p. 139-164. dez. 1999. 
BARROSO, J. O estado, a educação e a regulação das políticas públicas. Educação \& Sociedade. Campinas, SP, v. 26, n. 92, p. 725-751, out. 2005.

BARROSO, J. (Org.). A regulação das políticas públicas de educação: espaços, dinâmicas e actores. Lisboa: Educa, 2006.

BRASIL. Lei n. ${ }^{\circ}$ 9.394, de 20 de dezembro de 1996. Estabelece as diretrizes e bases da educação nacional. Diário Oficial [da República Federativa do Brasil], Brasília, DF, V. 134, n. ${ }^{\circ}$ 248, 23 dez. 1996. Seção I, p.177-197, 1996.

BRASIL. Lei n. ${ }^{\circ}$ 10.861, de 14 de abril de 2004. Institui o Sistema Nacional de Avaliação da Educação Superior - SINAES e dá outras providências. Diário Oficial da [República

Federativa do Brasil], Brasília, DF, V.141, n. . . 72, 15 abr., 2004. Seção I, p. 3-4, 2004.

BRASIL. Resolução CNE/CP n. ${ }^{0}$ 2/2015. Define as Diretrizes Curriculares Nacionais para a formação inicial em nível superior (cursos de licenciatura, cursos de formação pedagógica para graduados e cursos de segunda licenciatura) e para a formação continuada. Disponível em: $<$ http://portal.mec.gov.br/index.php?option=com_docman\&view=download\& alias=17719-res-cne-cp-002-03072015\&category_slug=julho-2015-pdf\&Itemid=30192> Acesso em: 3 jul. 2016 .

BRASIL. Orientações para cursos de Formação de Professores nas áreas de Didática, Metodologias e Práticas de Ensino: documento Base da Comissão SEB/MEC. Disponível em: $<$ http://portal.mec.gov.br/index.php?option=com_docman\&view=download\&alias =40811-documento-base-fevereiro-2016-pdf\&Itemid=30192>. Acesso em: 7 jul. 2016b.

BRASIL. Portaria Normativa n. ${ }^{\circ}$ 4, de 5 de agosto de 2008. Regulamenta a aplicação do conceito preliminar de cursos superiores, para fins dos processos de renovação de reconhecimento respectivos, no âmbito do ciclo avaliativo do SINAES instaurado pela Portaria Normativa n. 1, de 2007. Diário Oficial da [República Federativa do Brasil], Brasília, DF, v.145, n. ${ }^{\circ 150,} 06$ ago. 2008. Seção I, p. 19.

BRASIL. Nota Técnica n. ${ }^{0}$ 786/2013 DIREG/SERES/MEC. Sistematiza parâmetros e procedimentos para Renovação de Reconhecimento de Cursos, tomando como referência os resultados do ciclo avaliativo 2012, divulgado por meio do Conceito Preliminar de Curso CPC 2012, em conformidade com o Decreto Federal $n^{\circ}$ 5.773, de 9 de maio de 2006 e suas alterações, e na Portaria Normativa MEC $n^{\circ}$ 40, de 12 de dezembro de 2007, republicada em 29 de dezembro de 2010. Disponível em: < http://download.inep.gov.br/educacao_superior/ avaliacao_cursos_graduacao/legislacao_normas/2014/nota_tecnica_786_2013.pdf> Acesso em: 5 jul. 2016c.

BRASIL. Nota Técnica no 50006/2015/DIREG/SERES Sistematiza parâmetros e procedimentos para renovação de reconhecimento de Cursos, nas modalidades presencial e a distância, tomando como referência os resultados do ciclo avaliativo, divulgado por meio do Conceito Preliminar de Curso - CPC 2014. Disponível em: <http://portal.mec.gov.br/ index.php?option=com_docman\&view=download\&alias=32351-nota-tecnica-50008-seres2015-pdf\&category_slug=janeiro-2016-pdf\&Itemid=30192>. Acesso em: 4 nov. 2016. 
DALE, R. A promoção do mercado educacional ea polarização da educação. Educação Sociedade \& Culturas, n. 2, p. 109-139, Porto, 1994.

DIAS SOBRINHO, J. Avaliação institucional, instrumento da qualidade educativa: a experiência da Unicamp. In: DIAS SOBRINHO, J.; BALZAN, N. C. Orgs. Avaliação Institucional: teoria e experiências. 5 ed. São Paulo: Cortez, 2011.

DOURADO, L. F. Diretrizes Curriculares Nacionais para a formação inicial e continuada dos profissionais do magistério da educação básica: concepções e desafios. In Educação e Sociedade, Campinas, V. 36, n. ${ }^{\circ}$ 131, p. 239-324, abr./jun. 2015.

GIL, A. C. Métodos e técnicas de pesquisa social. 6.ed. São Paulo: Atlas, 2011.

GRIBOSKI, C. M. Regular e/ou induzir qualidade? os cursos de pedagogia nos ciclos avaliativos do Sinaes. 2014. 481f. Tese (Doutorado em Educação). Universidade de Brasília. Brasília, 2014.

INSTITUTO NACIONAL DE ESTUDOS E PESQUISAS EDUCACIONAIS ANÍSIO TEIXEIRA - INEP. Instrumento de Avaliação de Cursos de Graduação Presencial e a Distância. Disponível em: $<$ http://download.inep.gov.br/educacao_superior/avaliacao cursos_graduacao/instrumentos/2016/instrumento_2016.pdf> $>$. Acesso em: 15 maio 2016.

JORNET, J. M. Las dimensiones docentes y cohesión social: reflexiones desde la evaluación. Revista Iberoamericana de Evaluación Educativa, v. 5, n. 1 (e), 2012.

MOROSINI, M.C. Qualidade da educação universitária: isomorfismo, diversidade e equidade. Interface, Botucatu, v. 5, n. 9, p.89-102, ago 2001.

MOROSINI, M. C. Qualidade na educação superior: tendências do século. Estudos em Avaliação Educacional, São Paulo, v. 20, n. 43, p. 165-186, maio/ago. 2009. 